\title{
Making the Library Management Systems Acquisition: Achieving Resolution of a Tough Decision
}

\author{
Steven J. Bell and Cynthia Cronin-Kardon
}

\begin{abstract}
At some point in their careers, library administrators will likely be involved in the acquisition of a new library automation system. Whether it is a first-time acquisition or a migration from old to new, the decision is perhaps the most challenging the administrator will ever have to make. Despite an abundance of information in the library literature on the mechanical and managerial aspects of acquiring a new automated system, there is scant information on, or investigation into, the decision-making process that leads to the selection of an automation vendor. Based on the premise that the automation decision is both complex and risky, it is a decision fraught with ambiguity, uncertainty, and conflict. This study offers exploratory research on the automation decision process and those factors that lead to decision difficulty. Using the Garbage Can Model of Organizational Choice as a theoretical framework, this study uses decision resolution as a criterion of decision success. Based on research to identify factors that have enabled decision makers to achieve resolution, the authors of this study seek to make recommendations that will enable administrators to better manage a tough decision.
\end{abstract}

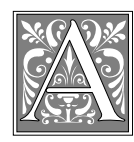

$t$ a regional conference, the director of a research library, in discussing his library's migration to a new library management system (LMS), succinctly summed up the attitude of LMS decision process participants. "It was exhilarating, but I wouldn't want to do it again for ten years." The decision to acquire a new library automation system, referred to here as an LMS, is straightforward. Whether acquiring a system for the first time or migrating to a new system, libraries make this decision for clear reasons. New sys- tems take advantage of the latest and emerging computer technology in creating a better search and work environment for staff and patrons. What is extremely difficult, and usually a source of tremendous uncertainty, is the selection of an automation vendor.

A central thesis of this article is that the decision to acquire new information technology is, as described by Paul C. Nutt, "a tough decision."1 Tough decisions are filled with ambiguity, uncertainty, and conflict. In selecting an LMS, the library organization must analyze its automation

Steven J. Bell is Director of the Gutman Library at the Philadelphia College of Textiles E Science; e-mail: Bells@philacol.edu. Cynthia Cronin-Kardon is a Reference Librarian in the Lippincott Library of the Wharton School at the University of Pennsylvania; e-mail: croninkc@wharton.upenn.edu. 
needs carefully and then determine which LMS product matches them. Rarely does an automation vendor offer a product with all the features a library requires, making the LMS decision one of tradeoffs. Should the library sacrifice its existing highly functional OPAC for vastly improved technical processing modules? Should the library align itself with a new vendor's untested, but promising, product or the less innovative, but marketproven, product of an established vendor? The decision is ripe for conflict among the decision participants. LMS decisions are characterized by their toughness.

To understand why this is, it is important to consider the following characteristics of the typical LMS decision situation:

- The technology changes rapidly so that information gathered last month may be totally irrelevant in light of today's developments.

- The information required to make this strategic decision is based on what vendors choose to disseminate. Is it wiser to go with vendor $\mathrm{A}$, who promises to deliver features in the next version six months from now, or vendor $B$, who can deliver today?

- The nature of the LMS technology marketplace is itself conducive to uncertainty. Owing to the small size and capitalization of many automation vendors, it is understandable that LMS decision makers are asking, "Will this company be here to support this product a year from now?" Though many vendors are reliable, the library systems industry has a number of elements that contribute to its unpredictability.

Nutt found that decision makers often ignored the uncertainty and conflict in tough decisions, which resulted in unsuccessful decision-making processes. ${ }^{2}$ Though the LMS acquisition is likely the riskiest and most crucial strategic decision that library administrators make, little is known about the decision-making process they use. As the literature review in this article will show, the study of decision-making for large-scale information technology in academic libraries is largely unexplored territory. This article's goal is to initiate an investigative study of automation acquisition and related decisionmaking behavior in academic libraries. In it is presented the results of a survey of libraries either migrating to a new LMS or making a first-time acquisition. The survey results will provide descriptive information about the decision structure and participants, and insights into how the decision process takes place. The study used the Garbage Can Theory of Organizational Choice as a framework for its analysis of LMS decision-making.

A key premise of this article is that the

\section{A key premise of this article is that the LMS decision process is complex and therefore subject to dysfunction.}

LMS decision process is complex and therefore subject to dysfunction. If the decision process lacks proper planning and management, the chances of decision failure increase. An objective in undertaking this research is to provide library administrators with a set of recommendations they can use to improve the LMS decision process. One thing is clear: The LMS decision is unlikely to become less ambiguous. Library administrators need information they can use to better manage decisions made under ambiguous conditions.

\section{A Theoretical Framework for Analysis}

One of the challenges of any analysis of decision making is in determining the criteria for judging successful decisions. From among different models used for decision-making analysis (e.g., rationalanalytical, bureaucratic, behavioral, political, etc.), the authors selected Michael D. Cohen, James G. March, and Johan P. Olsen's Garbage Can Model of Organizational Choice. ${ }^{3}$ This model describes a 
decision-making process that occurs in organized anarchies. The central features of an organized anarchy are problematic preferences, unclear technology, and fluid participation. As described by Cohen and March, an organized anarchy "does not know what it is doing. Its goals are either vague or in dispute [problematic preferences]. Its technology is familiar but not understood [unclear technology]. Its major participants wander in and out of the organization [fluid participation]."4 The model describes a dysfunctional decisionmaking process and suggests ways in which decision makers might better manage the process. It is often used to analyze decision-making in higher education. Cohen and March called the American college or university the prototypic organized anarchy.

With their greater staff homogeneity, hierarchical structures, and goal commonality, academic libraries tend to defy characterization as organized anarchies. This may be why the model rarely is used to describe academic libraries or to study library decision making. A notable exception is Joan Giesecke's study of a decision to choose the best system for governing a university library. ${ }^{5}$ This article, in comparing the political and garbage can models, concluded that library managers need to understand decision-making models to successfully manage decision processes. Selecting an appropriate strategy can influence decision outcomes. Giesecke found that the Garbage Can Model explained the diverse debates of the decision makers on a stream of unrelated topics and their inability to achieve resolution with unanimous support of the library staff.

The authors of this study think that the Garbage Can Model is particularly relevant for LMS decision-making. Owing to high-risk and ambiguity factors, these decisions tend to exhibit the dysfunctional behaviors common to decisionmaking in chaotic organizations. Cohen, March, and Olsen identified a series of properties that characterized an organization's garbage can decision process. Among these characteristics were the level of organizational energy expended on the decision process (high), the time required for the decision (lengthy), and the actions of the participants (fluid). The garbage can process describes a decision environment that results in decision resolution failure.

Decision resolution is one of three de-

\section{Oversight means that a decision, rather than being resolved, is essentially ignored.}

cision styles discussed by Cohen, March, and Olsen. It is an important concept in this analysis of LMS decision making. The anarchic organization makes decisions in one of three ways. Resolution is the optimal and normative manner of choice determination in organizations. In resolution, an appropriate choice matches a decision situation after a period of work by decision makers. It is the least common style in the garbage can decision process. What occurs most often is described as either oversight or flight. Oversight means that a decision, rather than being resolved, is essentially ignored. Decision makers do not decide but, rather, shift their energies to some other decision without concern for the original problem. Flight means that decision makers shift their energies to a new potential solution instead of resolving the decision based on existing and readily available solutions.

How do Cohen, March, and Olsen's decision styles relate to LMS decisionmaking? In analyzing LMS decision outcomes, resolution represents a primary criterion of success. If the decision makers resolve the decision, it indicates that the process is less characteristic of the Garbage Can Model than those decisions resulting in oversight or flight. In this study, the authors have tried to identify those decision process characteristics that 
are most conducive to resolution and those that contribute to oversight or flight. The authors seek to identify the behaviors most conducive to resolution in order to build a set of recommendations decision makers can follow in large-scale information technology acquisitions.

Often success is linked to decision outcomes. A successful decision outcome would be judged by criteria such as cost savings, improved system efficiencies, better service delivery, or more satisfied users. Outcomes can be measured, but this requires sufficient time after implementation to determine the level of success. In the case of an LMS, it may take a year or more, plus the collection of comparable data, to determine if system expenditures are lower, if search failure rates are lower, and if other measures of success are present. For purposes of this article, a successful decision is one that achieves resolution, regardless of the outcome, although the authors recognize that the two are strongly connected. Recommendations the authors make are linked primarily to identifying strategies that administrators should use for decision resolution. Successfully resolved decisions are completed more quickly, are less confusing to decision participants, and generally result in faster implementation

\section{Review of the Literature}

The LMS migration is a relevant topic for a study of decision-making behavior. In the past few years, many libraries either have acquired a new system or are planning to do so. The most comprehensive source of data on library automation trends is the "Automated System Marketplace" report. Published each April in $\mathrm{Li}^{-}$ brary Journal, this survey reports information on system installations, vendor revenues, market growth, and other LMS data.

The authors examined this annual report for the period between 1994 and 1997. In 1994, system migrations were not reported. However, vendors did report that new installations increased by 69 percent between 1992 and $1993 .{ }^{6}$ The 1995 survey was the first to report migrations, which numbered 151.7 The 1996 survey reported a dramatic 176 percent increase from 1994 to 1995, with the number of migrations rising from 151 to $418 .{ }^{8}$ For 1997 , the report authors did not report migration data, stating that "the issue is no longer whether or not to automate, but which system provides the best gateway to all electronic information." ${ }^{\prime 9}$ The 1997 report stated only that the automation marketplace remained stable.

To determine what beyond automation data is reported in the library literature about LMS decisions, the authors searched ERIC, LISA, and Information Science Abstracts. In addition, ABI/Inform was searched for articles on information technology decision-making. Books in Print, LC MARC Records, and local OPACs were searched for monographs on the topic. A considerable amount of information on library automation exists, but within that literature virtually nothing was found on the decision-making process for selecting an LMS. The automation literature is largely directed to the practical aspects of acquiring a new LMS, from developing system selection criteria to procedures for a successful implementation.

For example, John W. Head and Gerard B. McCabe's Insider's Guide to Library Automation contains a multitude of articles that provide practical advice on nearly every phase of the automation process, from developing local automation systems to selecting, buying, and installing them. ${ }^{10}$ Most of the authors discuss automation at their own sites. This book and others like it, such as John Corbin's Managing the Library Automation Project, which provides a request for proposal (RFP) sample, costing worksheets, and other practical tools for LMS selection, offer valuable reading for those embarking on an LMS acquisition. ${ }^{11}$

The journal literature contains a signifi- 
cant body of information on designating selection criteria, designing RFPs, and dealing with installation and hardware issues. For example, Edward R. Johnson identified pitfalls in selecting library automation systems. ${ }^{12}$ Based on his experience at Oklahoma State University, he concluded that automation selection must be particularly sensitive to rapid technology change, the psychological impact of delays, and the inclusion of library users in the selection process. Mona Couts and colleagues promoted the use of a concept paper as an alternative to the RFP. RFPs are typically time-consuming to produce and reflect current needs only. The concept paper provides vendors with a description of the library's vision of its future and requires the vendor to describe how its system's qualities match that vision. ${ }^{13}$ Their article is a good example of those that focus on a single facet of the selection process. Others focus on the experience of their own institution.

In an article providing a comprehensive, detailed look at a single institution's selection process, Philip Schwarz described everything from the factors leading to the system selection decision to RFP development and the structure of the decision committees. ${ }^{14}$ Although he concluded that the project was successful, there is no actual analysis of how this organization's approach to the decision process contributed to that success or how this process was successful owing to its differentiation from the process of libraries experiencing decision failure.

Surveys of groups of libraries help identify common elements of the selection process and provide practical advice on conducting the automation selection. Russell T. Clement surveyed twenty-one small institutions, focusing on factors used in selection decisions..$^{15}$ He found that cost and software issues were most significant. Julie Hallmark and C. Rebecca Garcia asked the automation administrators of thirty-three libraries what they would and would not do again in repeating their automation selection process. ${ }^{16}$ Here, again, the focus is on practical advice. These, and other articles of this type, largely ignore the structure of the decision process and the decision participants. They also fail to develop strategies that administrators might use to increase the likelihood of the process achieving resolution.

Discovering this lack of information on library automation decision processes, the authors identified additional articles on the general topic of decision making. Some, the authors postulated, may contain discussions of automation system selection. Douglas G. Birdsall and Oliver D. Hensley briefly mentioned the importance of decision committee structure in discussing library strategic planning. ${ }^{17}$ Others, including Robert S. Runyan and Carl H. Losse and Arlyle Mansfield Losse, discussed individual or group decisionmaking in libraries but fell short of providing concrete insight into decisionmaking for the acquisition of library technology. ${ }^{18-19}$ Although the literature search for this article indicated that automation decision makers can find an abundance of advice that may help with the mechanics of the selection process, a gap was found in the exploration of how a decision process structure can contribute to decision resolution.

\section{Methodology}

The intent of the design of this research instrument was twofold: first, to collect data about the structure of the LMS decision-making process; and second, to identify elements of the process that contribute to, or detract from, decision resolution. To achieve this, the authors mailed a survey questionnaire to a group of 142 academic libraries identified as having acquired or migrated to a new LMS in the past eighteen months. Several methods were used to identify survey participants, including:

- news from colleagues and list 


\begin{tabular}{|lrc|}
\hline \multicolumn{3}{|c|}{$\begin{array}{c}\text { TABLE 1 } \\
\text { Respondents by Collection Size } \\
\text { (N= 101) }\end{array}$} \\
\hline \hline Collection Size & Frequency & Percent \\
\hline Up to 100,000 & 26 & $25.7 \%$ \\
100,000 to 500,000 & 48 & 47.5 \\
500,000 to 1 million & 8 & 07.9 \\
1 million and greater & 19 & 18.8 \\
& 101 & 100.0 \\
\hline
\end{tabular}

servers;

- automation columns in library journals;

- customer notes and lists on vendor Web sites;

- solicitation of automation vendors for names of recent customers.

The questionnaires, with a cover letter explaining the research project, were mailed to each library's system director, if his or her name was known, or to the library director. The cover letter directed the recipient to have the chair of the selection committee complete and return the questionnaire. Most often, the chair was the library director. The first mailing resulted in the return of 71 questionnaires and a follow-up mailing brought in another 51, bringing the total number of questionnaires returned to 112 . The 112 completed surveys represented a response rate of 78 percent. Analysis of the returned surveys indicated that eleven were unusable, which adjusted the response rate of useable surveys to 71 percent. Initially, the primary criterion for participation in the study was migration to a new LMS within the last eighteen to twenty-four months. However, because 46 percent of the respondents were automating for the first time, it was decided to include these firsttime acquirers along with those migrating to new systems. The authors thought this might produce some interesting comparisons between first-time acquirers and those migrating.

Following are two levels of analysis of the collected data. First, a series of summary statistics examines the survey population. Of particular interest are the characteristics of the LMS selection process (length, deadlines, use of RFPs and consultants, etc.) and the structure of the selection committee (how organized, chairs, reporting, etc.). The nature of the selection process and its structuring are directly related to decision resolution. Second, a series of cross-tabulations was run to determine how strongly different decision process events correlated with decision difficulty. The results of these crosstabulations are used to test the following hypotheses:

- Migrating libraries experience more difficulty in resolving the decision than first-time acquirers do.

- Use of either an RFP or a consultant will result in less difficulty in resolving the decision.

- Limiting the number of vendors/ systems in the selection process will result in less difficulty in resolving the decision.

- Larger, more collaborative committee structures will result in less difficulty in resolving the decision.

- Decision processes that are lengthy result in difficulty in resolving the decision.

- Decision processes with specific deadlines are more likely to result in decision resolution.

\section{Survey Population}

\begin{tabular}{|c|c|c|}
\hline \multicolumn{3}{|c|}{$\begin{array}{c}\text { TABLE } 2 \\
\text { Respondents by Institution Type } \\
(\mathrm{N}=99)\end{array}$} \\
\hline Institution Type & Frequency & Percent \\
\hline Community college & 12 & $12.1 \%$ \\
\hline 4 -Year c & 40 & 40.4 \\
\hline University - no Ph.D. & 15 & 15.2 \\
\hline Research university & 32 & 32.3 \\
\hline Total & 99 & 100.0 \\
\hline
\end{tabular}

Frequency missing $=2$ 


\begin{tabular}{|lrc|}
\hline \multicolumn{3}{|c|}{$\begin{array}{c}\text { TABLE 3 } \\
\text { Reasons for Migration } \\
\text { (N = 101) }\end{array}$} \\
\hline \hline Reason for Migration & Frequency & Percent \\
\hline System not adequate & 22 & 28.6 \\
Reduce computing costs & 3 & 03.9 \\
Mandate: Univ. admin. & 10 & 13.0 \\
Mandate: Computer center & 2 & 02.6 \\
Failure of existing system & 1 & 01.3 \\
New technology/feature & 21 & 27.3 \\
Other & 18 & 23.4 \\
$\quad$ Total & 77 & 100.0 \\
\hline Frequency missing $=24$ & \\
\hline
\end{tabular}

Of the libraries responding to the questionnaire, 42 percent were public and 58 percent private. The majority were midsized, four-year colleges. Tables 1 and 2 identify the respondents by collection size and institution type. The larger representation of smaller libraries may account for the higher-than-expected response from first-time acquirers as opposed to migrating libraries. Whereas larger libraries take an automated environment for granted, smaller institutions with limited resources are still acquiring for the first time. Of those libraries that were migrating from an existing system, 13 percent were moving from a locally developed system to one purchased from an automation vendor.

Survey respondents were asked to give their reasons for choosing to migrate or acquire an LMS. The most frequently cited reasons were inadequate existing systems and desire for new technology and features (see table 3). Surprisingly, few indicated that the impetus for migration was cost reduction. Cost is considered a primary reason to migrate from an older, mainframe system to newer, client-server technology. The move to the new LMS was initiated by the library director in 46 percent of the cases. There was a fairly even distribution among three other sources of initiation (library strategic plan, joint library and computing strate- gic plan, committee action). In a few cases, just three percent, an automation crisis forced an LMS acquisition.

Length of the decision process, defined as starting when a selection committee is officially formed and ending when an official recommendation or selection decision is made, may indicate the level of difficulty encountered in the decision process. The authors wanted to know how long it took respondents to reach their LMS decision. Table 4 shows this distribution. The majority of the libraries completed their selection process in a year or less. Respondents' comments indicated that a number of the libraries were consortia members and that the LMS acquired would be the one that is compatible with those of other members. In these cases, the decision process will move faster because the choice options are defined more rigidly.

Decision process length can depend on whether the decision makers must meet a specific deadline. The imposition of a deadline on decision makers should cause them to reach a decision on time, whereas the lack of one will allow for procrastination. Although most of the respondents $(42 \%)$ had no deadline imposed on them, 29 percent did have a specific deadline and another 29 percent knew they needed to complete the decision within a specific three- to six-month time frame. Of those with a deadline or quasi-deadline, the vast majority (92\%) met it.

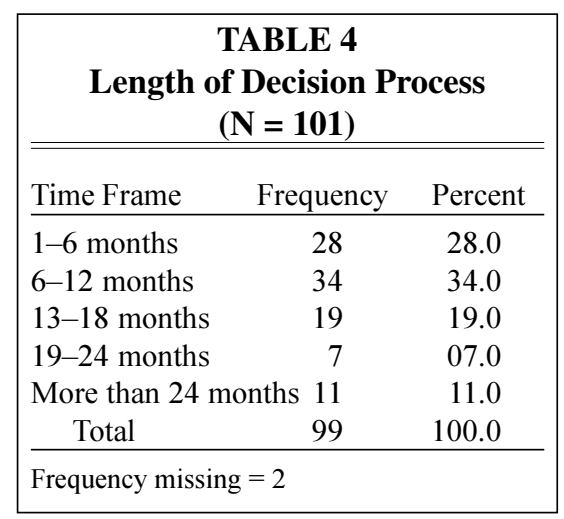


The authors wanted to know more about the respondents' decision committees and the impact of committee structure on decision resolution. The majority of the committees $(78 \%)$ consisted of fewer than ten members. Among those, committee size most frequently ranged from five to nine members. The tendency was for single decision committees, but in 13 percent of the cases, libraries reported using multiple committees. Multiple committees generally involved more than ten individuals. Committee mem-

\section{Cost is considered a primary reason to migrate from an older, mainframe system to newer, client-server technology.}

bership was nearly evenly divided between those organizations that involve only library staff in the decision (44\%) and those that create a committee composed of library and nonlibrary staff (56\%). Nonlibrary members were either faculty or computing staff. Students rarely served on LMS decision committees. Other administrators, such as business administrators or deans, were identified infrequently as committee participants. The person most often responsible for assigning participants to the LMS committee was the library director $(77 \%)$.

A primary characteristic of the organized anarchy is problematic preferences. By this, Cohen, March, and Olsen meant an organization without clear, understandable goals. In deciding which LMS to select, problematic preferences can be a source of difficulty. Within the library, participants may be unclear about the goals the organization is trying to achieve by acquiring a new system. Is the priority cost savings, a better OPAC, smootherrunning technical processing modules, or the need to establish computing independence from the university's central computer operation? Under these conditions, the participants develop greater ambigu- ity and confusion, resulting in the inability to reach resolution or to do so in a reasonable amount of time.

Two techniques available to libraries seeking to clarify their preferences are the use of RFPs and automation consultants. Although rigorous and time-consuming to produce, the RFP forces the decision committee to focus the intent of the decision process and should serve to eliminate or reduce problematic preferences. A consultant can help the decision committee sharpen its goals or aid in the RFP production. Whatever benefits a consultant may provide are certainly offset by the cost and extra time required for the consultant to study and understand the needs of the organization. An RFP was used by 46 percent of the respondents to select the LMS; only 28 percent used a consultant in the selection process.

LMS selection is complicated by the availability of dozens of system vendors. Libraries can narrow the field by targeting vendors whose products are geared to libraries of a particular size and type. For example, some vendors cater to the needs of large, academic research libraries whereas others focus on the needs of multiple-branch public libraries. The authors wanted to know how many vendors typically are involved in a library's choice process. It is important to note that the responses reflect the overall decision process and not necessarily the number of vendors on the respondent's "short list." The majority of the respondents (73\%) examined the systems of three to five vendors. Twelve percent included only one to two vendors, and 15 percent included more than five. Those including just one or two vendors in their selection process typically were consortia members.

Although, anecdotally, administrators often describe the LMS selection process as among the most difficult decisions of their professional careers, the survey results do not reflect this. When asked about the difficulty of the process, 61 percent of the respondents chose the description, 
"the decision process was straightforward, but not easy." Only 19 percent described the process as "difficult," and only a combined ten percent chose to describe it as "very difficult" or "the most difficult decision of my career." Respondents also were asked about the length of time needed to reach a selection decision. When asked if that time was less than needed, about right, or not enough, 69 percent indicated the length of the process was right. That 22 percent found the length of the process insufficient could indicate that although in those cases a decision was reached, more time may have allowed for a better resolution.

Overwhelmingly, respondents reported that they were "satisfied" (40\%) or "very satisfied" (51\%) with their selection. That question was framed as "how satisfied was the committee" with the selection. The answer may be biased coming from the committee chair. The chair may take the committee's ability to reach a decision as an indicator of satisfaction with the process. Committee participants can and do disagree with the chair about the selection. Participants who dissent with the selection decision may feel pressure to resolve the decision, which leads them to agree to a selection choice. However, in only ten percent of cases did respondents report anything other than a unanimous decision. Also, anything other than a complete decision disaster or total failure to reach a decision could be perceived as satisfaction with the process, even if certain elements of the process left participants unsatisfied with the outcome.

\section{Testing the Hypotheses and Discussion of Results}

To test the relationship between decision process variables and decision resolution, the authors used the chi-square test to determine the degree of independence or

\section{TABLE 5}

Decision Process Variables with Decision Difficulty

\begin{tabular}{lccc} 
Variable & Chi-Square & Phi & Probability \\
\hline Committee size* & 10.225 & .320 & 0.001 \\
Library size & 12.668 & .356 & 0.001 \\
RFP used & .054 & .02 & .816 \\
Consultants used & .347 & -.059 & .556 \\
Number of vendors & 3.29 & .069 & .18 \\
Migrate or new & 1.99 & .158 & .142 \\
Length of process & 3.265 & .071 & .181 \\
\hline
\end{tabular}

members or fewer) dependence between selected variables and decision difficulty. When necessary, the responses were collapsed into two categories (e.g., large/small) to create $2 x$ 2 tables. This increased cell size and permitted use of the same measure of correlation (Phi) for all cross-classifications. Phi varies from -1 (100\% negative correlation) to +1 ( $100 \%$ positive correlation). The key dependent variable was the degree of difficulty of the decision process. Difficulty to complete and inability to complete the process are indicators of decision resolution failure. The five possible responses to the questions (easy, straightforward, difficult, very difficult, and most difficult) were recoded into two categories (easy/ straightforward and difficult).

Of the six hypotheses tested, few are supported by the statistical tests. Table 5 shows the results of the analysis. Only two variables, committee structure and library size, had significant positive correlation to decision difficulty. Larger or more complex committees had more difficulty with decisions. Committees with more than ten members or libraries using multiple committees reported difficulty in decision making 57 percent of the time. Institutions using committees of ten or fewer people reported difficulty in decision-making 21 percent of the time. This suggests that smaller committees encounter less difficulty in achieving resolution, which refutes the authors' hypothesis that 
larger committees should encounter less difficulty in resolving decisions. The Garbage Can theory suggests larger committees bring more energy to the process, contributing to resolution.

The lack of correlation between several variables, including first or subsequent

\section{In retrospect, the process may seem easier and more satisfactory than it actually was.}

migration, use of RFP or consultant, number of vendors, or decision length of time and the degree of decision difficulty, suggests that in the LMS decision process, academic libraries cannot be said to reflect the Garbage Can Model of Organizational Choice. One exception is the positive correlation between library size and difficulty. Larger institutions had more difficulty than smaller institutions in the decision process. This provides some support to the authors' hypothesis that larger libraries experience more difficulty achieving resolution than small libraries. Larger libraries, with more complex issues to confront, are more likely to have problematic preferences.

A number of factors may account for both the weakness of the correlations and the authors' inability to convincingly prove the hypotheses. First, and perhaps most significant, is the research method itself. The survey method seems inadequate for analysis of a complex decision process. Although the survey proved useful for gathering statistical data on the respondents, it was less successful in determining what aspects of the process contributed to decision-making difficulties. The authors now believe that the case study method, using interviews with decision participants, would be more effective in allowing participants to discuss and elaborate on decision difficulty. The discrepancies between the anecdotal evidence and the survey results leads to the suspicion that a form of cognitive disso- nance explains why many respondents report little or no difficulty with the LMS selection process.

Having expended great effort in acquiring the LMS, the respondents, in recalling the process, now may perceive it quite differently. In retrospect, the process may seem easier and more satisfactory than it actually was. Whatever their beliefs about the difficulty of the process were at that time, the cognitive dissonance causes a different response to the survey questions. The authors think that the case study method would eliminate or minimize the effect of cognitive dissonance. When in-depth interviews are conducted, participants are more likely to provide greater detail and insights into the decision process that can allow the interviewer to more fully understand where difficulties occurred in the process. The interviewer also has the ability to use probing questions to help the respondent reflect on how the structure of the decision committees, other decision makers, the vendors, and the organization contributed to the challenges of acquiring the new LMS.

The survey population may be the source of additional problems. A larger number of respondents were first-time LMS acquirers than initially anticipated. The authors believe that migrating to a new vendor makes for a more difficult decision and that the inclusion of too many first-time acquirers may skew the results toward suggesting that the process is easy. Migrating to a new system involves more risk because the challenge is to acquire a system that loses none of the functionality of the existing system but, rather, brings improvement in all areas while decreasing computing costs and increasing processing speed. Moving from no automation to an automated system is much easier. No matter what one acquires, it is sure to be an improvement. Those migrating have more to lose. No library director wants to hear campus constituencies complaining that the new 
system, despite the cost of the acquisition, just is not as good as the old one.

The survey population also included many small libraries. In those organizations, the decision process may indeed be simpler. The decision committees are smaller and typically include the library director (who frequently makes the final decision), and lack of funds may inhibit the small library's ability to conduct an extensive decision-making process. In smaller libraries, a quick, simple decision process may be the norm. A closer inspection of the responses of the few large research university libraries in the survey population indicated that they were more likely to characterize the process as somewhat difficult, very difficult, or among the most difficult decisions made. Larger research libraries have a much broader constituency to serve, have the resources to consider multiple vendors, and are likely to have larger, more complex decision committee structures. Their need to involve nonlibrary personnel in the decision process and to gain support, feedback, and buy-in from a more diverse group of constituents also contributes to greater decision complexity. It may be that large libraries are experiencing the greatest difficulty in achieving decision resolution. However, when looking at just the large libraries, the sample size became too small to test the hypotheses reliably.

\section{Future Research}

Although the statistical analysis of the survey data failed to prove the majority of their major hypotheses, the authors maintain that the Garbage Can Model of Organizational Choice is a viable model for describing the LMS decision process. The authors know that many participants in the LMS decision acknowledge the difficulty in making this strategic, costly choice. The authors also know there are factors that can impede the decision maker's ability to achieve decision resolution. The challenge is to determine the best method to discover what those fac- tors are and then to develop recommendations to help LMS decision makers achieve resolution more easily.

The authors see a need for further LMS decision-making research and recommend that it utilize the case study research method. The research should target libraries just embarking on the process of migrating from an old LMS. The researchers should cover the entire decision process and include participant observation and interviews. This will be more timeconsuming and costly, but it is a proven method used by decision-making scholars to study all types of strategic decisions. Future research should involve a better mix of libraries or examine specific segments of the library community, such as those at the research university level. More difficulty is likely to be experienced at larger, more complex library organizations. If possible, comparative research on different-size organizations should be considered.

What benefits can be gained from this research? First, there is a need to determine under what conditions and for what libraries the LMS decision process is apt to produce the dysfunctional behaviors that cause flight and oversight. Not all libraries will face great ambiguity in acquiring a new LMS. For example, a consortium member acquiring the system used by all consortia members. However, should the consortium leadership choose to migrate to a new LMS, that would be a far riskier venture and one more susceptible to those conditions conducive to decision failure. Next, a set of prescriptive measures should be identified that allows administrators and decision makers to create an improved decision process that either eliminates garbage can properties or minimizes their impact.

The critical areas for study of the LMS decision process are those behaviors that contribute to, or detract from, resolution. Using the Garbage Can Model of Organizational Choice as a framework for analysis suggests focusing on two areas: 
- Decision structures: Who should have access to the decision process? Does the decision process work best when only a few top administrators are involved, or is it best to invite individuals from throughout the organization to participate? Do collaborative structures (those involving a large cross-section of library and nonlibrary personnel) work better than the limited structures?

- Problematic preferences: How well do the decision makers understand the goals of the decision process? Are their expectations of their ability to identify and acquire the best LMS for the institution realistic, and are they prepared to anticipate and manage the inherent risks and constraints of complex technology acquisitions? Does use of the RFP help decision makers better define their decision process goals?

In addition, researchers should examine other factors that may lead to flight

\section{Under increased conditions of constrained resources and complex and technically confusing options, acquiring information technology is not likely to get easier or less risky.}

or oversight. These include the number of vendors that decision makers choose to include in the process, the length of time the process takes and whether a deadline is imposed on the decision makers, and how the degrees of complexity and ambiguity differ in first versus subsequent LMS acquisitions because prescriptive measures may vary in each case (although automated systems are soon likely to be so ubiquitous that first-time acquirers will have all but disappeared).

The goal of future research should be to identify specific actions that decision makers can take to overcome the challenges of making choices in an environment characterized by many unknown factors. Such recommendations may take the form of guidelines or tasks that ad- ministrators can follow to achieve decision resolution. For example:

- Form committees that provide wide campus representation.

- Limit the number of vendors to no more than three.

- Begin actively examining vendor products only when the goals for the acquisition are clearly defined.

- Use an RFP to help focus goals if appropriate.

- Impose a deadline of one year from the day vendors are identified to actual resolution.

Whatever form future research takes, it will help for the profession to define measurable criteria for evaluating successful LMS acquisitions. Although this study has concerned itself primarily with the decision process, what comes after the LMS decision is far more important. No matter what recommendations future researchers make to decision makers, their efforts will be in vain if they fail to connect decision-making behavior to effective decision outcomes. Longitudinal studies of libraries are needed to determine whether long-term factors such as savings to libraries, system performance improvements, or increases in patron satisfaction levels are actually achieved. If the case study method is used, participating libraries could remain under observation for a two- to five-year period after system implementation. This would provide researchers with the long-term data needed to assess the factors that lead to successful decisions and outcomes-and the relationship between the two.

\section{Conclusions}

The LMS decision maker already has an abundance of advice on various mechanical and procedural aspects of acquiring an automated system. The decision-making dimensions of the LMS selection process should be explored further so that administrators can better manage these decision situations. If they fail to manage LMS and other technology choice oppor- 
tunities effectively, the decision situation becomes dysfunctional. Choice opportunities become garbage can decisions, and the process loses inertia as it grinds down and becomes mired in conflict and confusion, leaving decisions unresolved. Guided by recommendations to help them acknowledge the inherent ambiguity of this process and to give attention to structuring the decision process, decision makers can manage the dysfunctional behaviors. Proper management of the decision process will lead to good information technology decisions. ${ }^{20}$

In an era of technological uncertainty, one sure thing is that administrators will be faced with more complex strategic technology acquisition decisions. The results of further study into LMS decisionmaking may have applications as a general set of guidelines that help library administrators confront the challenges of choosing the technologies needed to build the libraries of the next century. Under increased conditions of constrained resources and complex and technically confusing options, acquiring information technology is not likely to get easier or less risky. Thinking back to the library director whose last LMS acquisition created mixed emotions of excitement and dread, it is hoped that by the next time this director enters the LMS market, our understanding of the acquisition process allows far more control and manageability of this strategic decision. Acquiring an LMS will still be a tough decision, but not so tough that library directors might opt to retire rather than face it again.

The authors would like to acknowledge Dr. Michael Halperin for his assistance with the instrument design, data collection, analysis, and interpretation of the data; and Jane Bryan for her helpful review and comments.

\section{Notes}

1. Paul C. Nutt, "Preventing Decision Debacles," Technological Forecasting and Social Change 38, no. 2 (1990): 159-74.

2. Ibid.

3. Michael D. Cohen, James G. March, and Johan P. Olsen, "Garbage Can Model of Organizational Choice," Administrative Science Quarterly 17, no. 2 (1972): 1-25.

4. Michael D. Cohen and James G. March, Leadership and Ambiguity: The American College President (New York: McGraw-Hill, 1974), 3.

5. Joan Giesecke, "Recognizing Multiple Decision-making Models: A Guide for Managers," College \& Research Libraries 54 (Mar. 1993): 103-13.

6. Jose-Marie Griffiths and Kimberly Kertis, "Automated System Marketplace: 1994," Library Journal 119 (Apr. 1994): 50-59.

7. Jose-Marie Griffiths and Gerald Lundeen, "The Changing Face of Automation: Automated System Marketplace 1995," Library Journal 120 (Apr. 1995): 44-54.

8. Jeff Barry, Jose-Marie Griffiths, and Peiling Wang, "Jockeying for Supremacy in a Networked World: Automated System Marketplace 1996," Library Journal 121 (Apr. 1996): 40-51.

9. Theresa Pepin, Jeff Barry, and W. David Penniman, "The Competitive Edge: Expanded Access Drives Vendors," Library Journal 122 (Apr. 1997): 47-56.

10. John W. Head and Gerald B. McCabe, eds., Insider's Guide to Library Automation: Essays of Practical Experience (Westport, Conn.: Greenwood Pr., 1993).

11. John Corbin, Managing the Library Automation Project (Phoenix, Ariz.: Oryx Pr., 1985).

12. Edward R. Johnson, "Lessons Learned from Unsuccessful Experiences," Journal of Academic Librarianship 19 (Nov. 1993): 306-7.

13. Mona Couts, Charles Gilreath, Joe A. Hewitt, and John Ulmshneider, "Use of a General Concept Paper As RFP for a Library System: A New Model for Library System Procurement," Advances in Library Automation and Networking 5 (1994): 177-202.

14. Philip Schwarz, "Selection of an Automated Library System for the University of Wisconsin Cluster Libraries," Information Technology and Libraries 6 (Mar. 1987): 40-56.

15. Russell T. Clement, “Cost Is Not Everything," Library Journal 110 (Oct. 1985): 52-55. 
16. Julie Hallmark and C. Rebecca Garcia, "System Migration: Experiences from the Field," Information Technology and Libraries 11 (Dec. 1992): 149-59.

17. Douglas G. Birdsall and Oliver D. Hensley, "A New Strategic Planning Model for Academic Libraries," College \& Research Libraries 55 (Mar. 1994): 149-59.

18. Robert S. Runyon, "Some Principles of Effective Decision Making in American Libraries," Journal of Academic Librarianship 8 (July 1982): 144-150.

19. Carl H. Losse and Arlyle Mansfield Losse, "Creative Thinking in Decision Making: A Bibliography," College E Research Libraries 48 (July 1987): 297-301.

20. Steven J. Bell, A Critical Analysis of the Strategic Decision Making Process for Information Technology in Academic Libraries (Ed.D. diss., University of Pennsylvania, 1997). 